Quim. Nova, Vol. 35, No. 9, 1746-1751, 2012

\title{
ABSORÇÃO DE BÁRIO POR PLANTAS DE ARROZ (Oryza sativa L.) E MOBILIDADE EM SOLO TRATADO COM BARITINA SOB DIFERENTES CONDIÇÕES DE POTENCIAL REDOX
}

\author{
Erica Souto Abreu Lima*, Nelson Moura Brasil do Amaral Sobrinho, Marcio Osvaldo Lima Magalhães, Jair do Nascimento \\ Guedes e Everaldo Zonta \\ Departamento de Solos, Instituto de Agronomia, Universidade Federal Rural do Rio de Janeiro, BR 465, km 7, 23890-000 \\ Seropédica - RJ, Brasil
}

Recebido em 13/12/11; aceito em 27/5/12; publicado na web em 24/8/12

\begin{abstract}
BARIUM ABSORPTION BY RICE PLANTS (Oryza sativa L.) AND MOBILITY IN SOIL TREATED WITH BARITE UNDER DIFFERENT REDOX POTENTIAL CONDITIONS. Two parallel tests were carried out to evaluate barium solubility in soils treated with barite under reducing conditions: one in leaching columns and another with potted plants cultivated with rice. Soils were treated with three doses of barite and kept at two humidity levels. The reduction $(-200 \mathrm{mV})$ condition promoted an increase in barium in the geochemical fraction of higher liability, higher concentrations of barium in the leached extracts, and higher absorption by rice plants. As a result of increased uptake and accumulation of barium, the plants showed stunted growth
\end{abstract}

Keywords: contamination; leaching; redox potential.

\section{INTRODUÇÃO}

O bário está presente naturalmente como elemento traço em rochas ígneas e sedimentares. Embora não seja encontrado livre na natureza, ocorre em uma série de compostos, mais comumente como sulfato de bário (baritina) e, em menor escala, como carbonato de bário (witherite). ${ }^{1} \mathrm{~A}$ inércia química, alta densidade, abundância relativa e os baixos custos de extração e beneficiamento fazem da baritina a principal fonte de bário ou sais de bário, conferindo uma intensa utilização na indústria química, principalmente, na atividade de perfuração e prospecção de petróleo e gás. ${ }^{2}$

A exploração intensiva de reservas minerais tem aumentado o conteúdo de bário no meio ambiente. Esta atividade produz resíduos que geralmente são dispostos no solo em torno da área de mineração. Esses resíduos quando dispostos em solos com drenagem deficiente, bem como em microssítios específicos de anaerobiose no interior de agregados, podem sofrer reações de redução, alterando a dinâmica do elemento no solo. ${ }^{3}$

Diversos estudos têm sido realizados para avaliar os impactos da prospecção de minerais. Raghu, ${ }^{4}$ estudando a acumulação de elementos nas plantas e nos solos em torno de áreas de mineração de baritina na Índia, evidenciou a presença de espécies vegetais com características indicadoras de áreas contaminadas por bário.

Apesar do bário contido na baritina ser relativamente imóvel e pouco biodisponível, devido à baixa solubilidade em água $\left(2,47 \mathrm{mg} \mathrm{L}^{-1}\right.$ a $\left.25^{\circ} \mathrm{C}\right),{ }^{5}$ não se conhece a magnitude das alterações na sua dinâmica em condições redutoras dos solos $(-200 \mathrm{mV})$. Esta condição promove alterações no equilíbrio natural do solo, que desencadeiam uma série de transformações nas características físicas, biológicas, químicas e eletroquímicas desse meio. ${ }^{6}$ Dentre essas alterações tem-se a sucessão de microrganismos no solo, que utilizam em seu metabolismo os compostos oxidados como receptores de elétrons, que obedece à sequência: nitrato, óxidos de manganês, óxidos de ferro, sulfato e carbono. Dessa forma, estudos indicam que a baritina pode servir como fonte de sulfato para as bactérias redutoras de sulfatos a sulfetos, promovendo o aumento da solubilidade e uma possível liberação do bário para o ambiente. ${ }^{7,8}$

\footnotetext{
*e-mail: ericaabreulima@gmail.com
}

Magalhães et al., ${ }^{8}$ estudando a mobilidade de bário em solo tratado com sulfato de bário sob condição de oxidação e redução, encontraram, na condição redutora, teores de bário no extrato lixiviado acima dos padrões de potabilidade, evidenciando o risco de contaminação do lençol freático.

Em ensaio com plantas de arroz cultivadas em Latossolo tratado com $\mathrm{BaSO}_{4}$ P.A, Magalhães, ${ }^{9}$ observou que a condição de saturação promoveu maior absorção e acúmulo de bário pelas plantas. Suwa et al. ${ }^{10}$ verificaram que a aplicação de bário inibiu a atividade fotossintética afetando o desenvolvimento das plantas, principalmente a produtividade, evidenciando assim o efeito fitotóxico do elemento.

Diante do exposto, este trabalho teve como objetivo principal avaliar se em condições redutoras ocorreria aumento da solubilização e, como consequência, liberação do bário no solo, potencializando o risco de contaminação das águas subterrâneas e a transferência desse elemento para a cadeia trófica.

\section{PARTE EXPERIMENTAL}

O estudo da dinâmica do bário foi realizado através de dois experimentos, conduzidos em paralelo, sendo um em colunas de lixiviação e o outro em vasos com plantas de arroz.

Foi utilizado o horizonte A de um Latossolo Vermelho Amarelo (20 cm de profundidade), amostrado sob condições naturais, no município de Pinheiral, Estado do Rio de Janeiro, Brasil. O solo coletado apresentava valor de $\mathrm{pH}$ de 5,8, teor de argila de $596 \mathrm{~g} \mathrm{~kg}^{-1}$, soma de bases de 5,2 $\mathrm{cmol}_{\mathrm{c}} \mathrm{dm}^{-3}$ e CTC pH 7,0 de 9,7 $\mathrm{cmol}_{\mathrm{c}} \mathrm{dm}^{-3}$, conforme EMBRAPA. ${ }^{11}$ Também foi determinado o teor pseudototal de bário através de digestão com água régia, ${ }^{12}$ onde a concentração de bário foi de $223 \mathrm{mg} \mathrm{kg}^{-1}$.

$\mathrm{O}$ delineamento experimental foi o inteiramente casualizado, em esquema fatorial $(4 \times 2)$, composto por testemunha +3 doses de bário, 2 teores de umidade e 4 repetições, totalizando 32 unidades experimentais (Tabela 1). Nos ensaios foram aplicadas doses de bário segundo os valores orientadores do CONAMA, ${ }^{13}$ sendo a baritina utilizada como fonte de bário (Tabela $1 \mathrm{~S}$, material suplementar). Este material foi fornecido pela Petrobrás Unidade de Negócios de Exploração e Produção do Rio de Janeiro - UN-RIO, onde é utilizado como aditivo ao fluido de perfuração de poços de petróleo. 
Os tratamentos aplicados ao solo foram: testemunha - sem aplicação de bário, sendo os teores naturais apresentados pelo solo coletado; dose de $100 \mathrm{mg} \mathrm{kg}^{-1}$; dose de $300 \mathrm{mg} \mathrm{kg}^{-1}$ e dose de 3000 $\mathrm{mg} \mathrm{kg}{ }^{-1}$. As doses utilizadas foram estabelecidas para que quando adicionadas ao solo, determinassem uma condição de um solo com concentração próxima ao valor de investigação (300 mg kg-1); uma condição com aproximadamente o dobro do valor de investigação e uma condição extrema, com valores de dez vezes o valor de investigação, segundo o CONAMA. ${ }^{13}$

O solo foi mantido em duas condições de umidade: $70 \%$ da capacidade de campo e saturação com lâmina de água $(5 \mathrm{~cm})$ na superfície do solo. A umidade durante a condução do experimento foi mantida da seguinte forma: para o solo saturado foi padronizada uma altura da lâmina d'água onde, diariamente, era realizado o monitoramento para que permanecesse constante. A partir do volume necessário para completar a altura da lâmina, estimava-se o quanto foi perdido e adicionava-se o mesmo volume nos vasos a $70 \%$ da capacidade de campo.

Para o ensaio de lixiviação foram construídas colunas de PVC, com $100 \mathrm{~mm}$ de diâmetro interno e $60 \mathrm{~cm}$ de altura. Na parte inferior de cada tubo foi encaixado um funil para facilitar a coleta do extrato. Para evitar o escoamento preferencial pelas paredes dos tubos colocou-se parafina inerte no limite entre a parede da coluna e o solo.

Tanto os vasos quanto as colunas receberam o volume de $5 \mathrm{dm}^{3} \mathrm{de}$ solo, que foi seco ao ar e peneirado em tamis de malha de 4,0 $\mathrm{mm}$. O solo das unidades que receberam as doses de bário foi misturado com a baritina manualmente, em sacos plásticos, em quantidade suficiente para atingir a respectiva dose. A seguir, as unidades experimentais foram preenchidas com o solo devidamente homogeneizado.

Após receberem as doses de bário, aplicou-se volume de água em quantidade de forma a atingir os teores de umidade propostos na pesquisa. Em seguida, cobriu-se com papel alumínio, para evitar a perda de água por evaporação.

Duas horas após a incubação dos tratamentos, foram determinados os valores de $\mathrm{pH}$ e Eh. Posteriormente, esta determinação foi realizada semanalmente, até a estabilização do potencial redox a valores, em torno de $-200 \mathrm{mV}$, necessários para que ocorra a redução do sulfato a sulfeto, em solo saturado. Esses valores foram atingidos no prazo de 10 semanas, porém se aguardou 30 dias para que as reações de redução se estabilizassem. Após atingir os valores de potencial redox desejados, foi realizado o fracionamento geoquímico para o elemento bário e iniciados os ensaios de lixiviação nas colunas e o transplantio das mudas de arroz nos vasos.

Para a realização do fracionamento geoquímico, após o período de incubação, foi realizada a amostragem do solo em três profundidades na coluna com um auxílio de um minitrado. Em seguida, as amostras simples foram misturadas obtendo-se uma amostra composta de cerca de $50 \mathrm{~g}$, equivalente a $1 \%$ da massa total de solo da coluna. O método utilizado foi o BCR (Community Bureau of Reference) desenvolvido por Ure et al.,${ }^{14}$ onde as frações geoquímicas e a marcha da extração sequencial são definidas como: F1 (fração ácido solúvel): extraída com solução de ácido acético $0,11 \mathrm{~mol} \mathrm{~L}^{-1}$; F2 (fração ligada aos óxidos de ferro e manganês): extraída com solução de cloridrato hidroxilamina $0,1 \mathrm{~mol} \mathrm{~L}^{-1} ; \mathrm{F} 3$ (fração ligada à matéria orgânica): extraída com as soluções de peróxido de hidrogênio $8,8 \mathrm{~mol} \mathrm{~L}^{-1} \mathrm{e}$ acetato de amônio 1,0 mol L-1 e F4 (fração residual): extraída com água régia.$- \Sigma$ das frações anteriores.

O ensaio de lixiviação consistiu na aplicação de uma lâmina de água equivalente à precipitação pluviométrica de $200 \mathrm{~mm} \mathrm{dia}^{-1}$. Para o tubo de PVC de $100 \mathrm{~mm}$ de diâmetro, o volume de água aplicado para atingir $200 \mathrm{~mm}$ de carga hidráulica foi de $1,6 \mathrm{dm}^{3}$ coluna $^{-1}$. O extrato foi dividido em volumes de $200 \mathrm{~mL}$, que correspondeu a 1/8 do volume de poro da coluna de solo. O volume de poros foi estimado através da diferença de peso obtido entre a coluna de solo saturado e a coluna seca.

Para a condição de saturação, com presença de lâmina, foi adicionada água deionizada e coletado, simultaneamente, na saída do funil o volume de $200 \mathrm{~mL}$ em recipientes plásticos descontaminados. Para as colunas que estavam a $70 \%$ da capacidade de campo, foi adicionada água até a saturação e só após foi colocado o volume de água correspondente. Para cada coluna foram recolhidas 8 garrafas plásticas contendo $200 \mathrm{~mL}$ do extrato lixiviado. Após a coleta, os extratos passaram por processo de filtração lenta, que teve como finalidade eliminar possíveis partículas de solo que se encontravam em suspensão. Os extratos foram analisados quanto ao teor de bário solúvel e foram comparados a valores orientadores para potabilidade, segundo a Resolução 420 do CONAMA. ${ }^{13}$ Após a determinação das concentrações do elemento nos extratos lixiviados, calculou-se a massa de bário removida em cada volume coletado, sendo a soma das massas o total de bário removido pela lixiviação.

A condução do ensaio em vasos foi realizada da mesma forma que o ensaio em colunas. Entretanto, ao atingir valores de potencial redox desejado $(-200 \mathrm{mV})$ para o solo saturado, foi realizado o cultivo do arroz (Oryza sativa L.) cultivar Bico Ganga, por meio de mudas. Estas foram produzidas a partir de germinação em vasos, em fitotron. As mudas após serem retiradas do fitotron, permaneceram 3 dias em casa de vegetação para serem aclimatadas, dessa forma reduzindo possível estresse. O transplantio das mudas foi realizado 15 dias após a germinação, quando foram selecionadas pelo tamanho e vigor. Em cada vaso, foram colocadas 6 mudas e após aproximadamente 20 dias foi realizado o desbaste, onde permaneceram apenas 2 plantas por vaso. Foi realizada adubação de forma parcelada, sendo aplicada em superfície no plantio a quantidade equivalente a $80 \mathrm{~kg} \mathrm{ha}^{-1} \mathrm{de}$ $\mathrm{N}, 40 \mathrm{~kg} \mathrm{ha}^{-1}$ de $\mathrm{P}$ (em dose única) e $40 \mathrm{~kg} \mathrm{ha}^{-1} \mathrm{de} \mathrm{K}$. Após 40 dias foi realizada adubação de cobertura aplicando-se $40 \mathrm{~kg} \mathrm{ha}^{-1}$ de $\mathrm{N} \mathrm{e}$ $40 \mathrm{~kg} \mathrm{ha}^{-1}$ de $\mathrm{K}$. As quantidades de nutrientes adicionados aos solos foram determinadas após a obtenção dos resultados da análise química e o recomendado para a cultura do arroz.

As plantas de arroz foram coletadas com aproximadamente 140 dias, correspondente ao ciclo vegetativo da cultivar. Após a coleta, as plantas foram separadas em raiz, parte aérea e grãos. Com a finalidade de retirar o excesso de solo das raízes foi realizada, inicialmente, uma lavagem em água comum e, posteriormente, em água destilada e deionizada. As partes das plantas foram secas em estufa de circulação forçada de ar a $60^{\circ} \mathrm{C}$ até atingirem peso constante e moídas em moinho tipo Willey com malha de $2 \mathrm{~mm}$.

O desenvolvimento das plantas foi avaliado quanto ao teor de matéria seca das raízes, parte aérea e dos grãos (cheios e vazios). Os teores de bário foram determinados nas diferentes partes da planta, após digestão nitroperclórica 6:1, conforme Tedesco et al.. ${ }^{15}$ Com base nas concentrações e produção de matéria seca, foram calculadas as quantidades acumuladas do elemento nas raízes, parte aérea e grãos.

Os teores de bário nos extratos de solo e planta foram quantificados em aparelho de espectrômetro de emissão por plasma (ICP-OES), marca Perkin Elmer, modelo Optima 3000, com LD (mg kg-1) de 0,036 e LQ $\left(\mathrm{mg} \mathrm{kg}^{-1}\right)$ de 0,36 para bário. O limite de detecção (LD) do método foi calculado pela média dos valores dos brancos mais três vezes o desvio-padrão do branco de todas as análises (10 repetições). Para validação da determinação do teor pseudototal de bário no solo e nas plantas, utilizaram-se os seguintes materiais certificados de referência: NIST SRM 2709a - San Joaquin Soil e SRM 1573a Tomato Leaves, que apresentaram concentrações de bário de $979 \pm$ $28 \mathrm{mg} \mathrm{kg}^{-1}$ (95\% de recuperação) e $63 \mathrm{mg} \mathrm{kg}^{-1}$ (93\% de recuperação), respectivamente, estando dentro dos intervalos admitidos pelo NIST como normais para as amostras de solo e planta.

Os dados foram avaliados por análise de variância com aplicação 
do teste $F(\rho \leq 0,05)$, sendo os valores médios comparados pelo teste de Tukey $(\rho \leq 0,05)$. Todas as análises estatísticas foram feitas por meio do programa estatístico SAEG versão 9.0 (Fundação Arthur Bernardes na UFV, Viçosa-MG).

\section{RESULTADOS E DISCUSSÃO}

A variação do potencial redox nos diferentes teores de umidade e a relação entre o Eh e o $\mathrm{pH}$ em função do período de alagamento são apresentados na Figura 1.

Na Figura 1A observa-se que o solo apresentou valores de Eh oscilando em torno de $+400 \mathrm{mV}$ para a condição de $70 \%$ da capacidade de campo, estando dentro da faixa considerada para solos oxidados. Segundo Camargo et al. ${ }^{16}$ altos valores de Eh estão associados à presença de oxigênio e outras espécies oxidadas, enquanto baixos valores estão associados com espécies reduzidas.

Para o solo saturado observa-se que logo na primeira semana de alagamento ocorreu uma queda brusca e, a partir da décima semana, houve a estabilização dos valores de Eh em torno de $-200 \mathrm{mV}$, faixa desejada no experimento. Solos que apresentam esses valores são considerados como muito reduzidos e sob essas condições poderá ocorrer a redução de sulfato a sulfeto pelas bactérias (BRS) presentes nesse ambiente de extrema redução, ${ }^{7}$ visto que na reação intermediada por sistemas biológicos, o oxigênio é o principal receptor de elétron, mas na sua ausência outros constituintes podem funcionar como receptores. ${ }^{16}$ Essa condição altera o equilíbrio dos elementos e dos compostos do solo, resultando em importantes alterações químicas, físicas, biológicas e mineralógicas, sendo a mudança mais significativa o decréscimo no potencial redox. ${ }^{17}$

Para avaliação das atividades de prótons e de elétrons com o decorrer das semanas de alagamento, construiu-se um diagrama de Eh-pH, ${ }^{18}$ Figura 1B. Observa-se que antes do alagamento o solo apresentava valores de Eh de $+450 \mathrm{mV}$ e valores de $\mathrm{pH}$ próximos a 5,$0 ;$ com o decorrer das semanas de alagamento o Eh foi diminuindo até estabilizar em valores próximos a $-200 \mathrm{mV}$, enquanto que o $\mathrm{pH}$ aumentou até estabilizar próximo à neutralidade $(7,0)$. Solos com valores de Eh baixo geralmente apresentam valores de $\mathrm{pH}$ mais elevados. $\mathrm{O}$ pH do solo aumenta porque os elétrons excedentes da respiração dos organismos são descarregados em compostos que se reduzem, os quais reagem com o $\mathrm{H}^{+}$do meio, diminuindo sua concentração. ${ }^{16}$

A distribuição do bário nas diferentes frações geoquímicas, obtida pelo método BCR, é apresentada na Tabela 1. Observa-se que para fração ácido solúvel (F1), fração ligada a óxidos (F2) e fração ligada à matéria orgânica (F3) há um aumento significativo em função das doses para ambos os teores de umidade. Na fração residual (F4), em
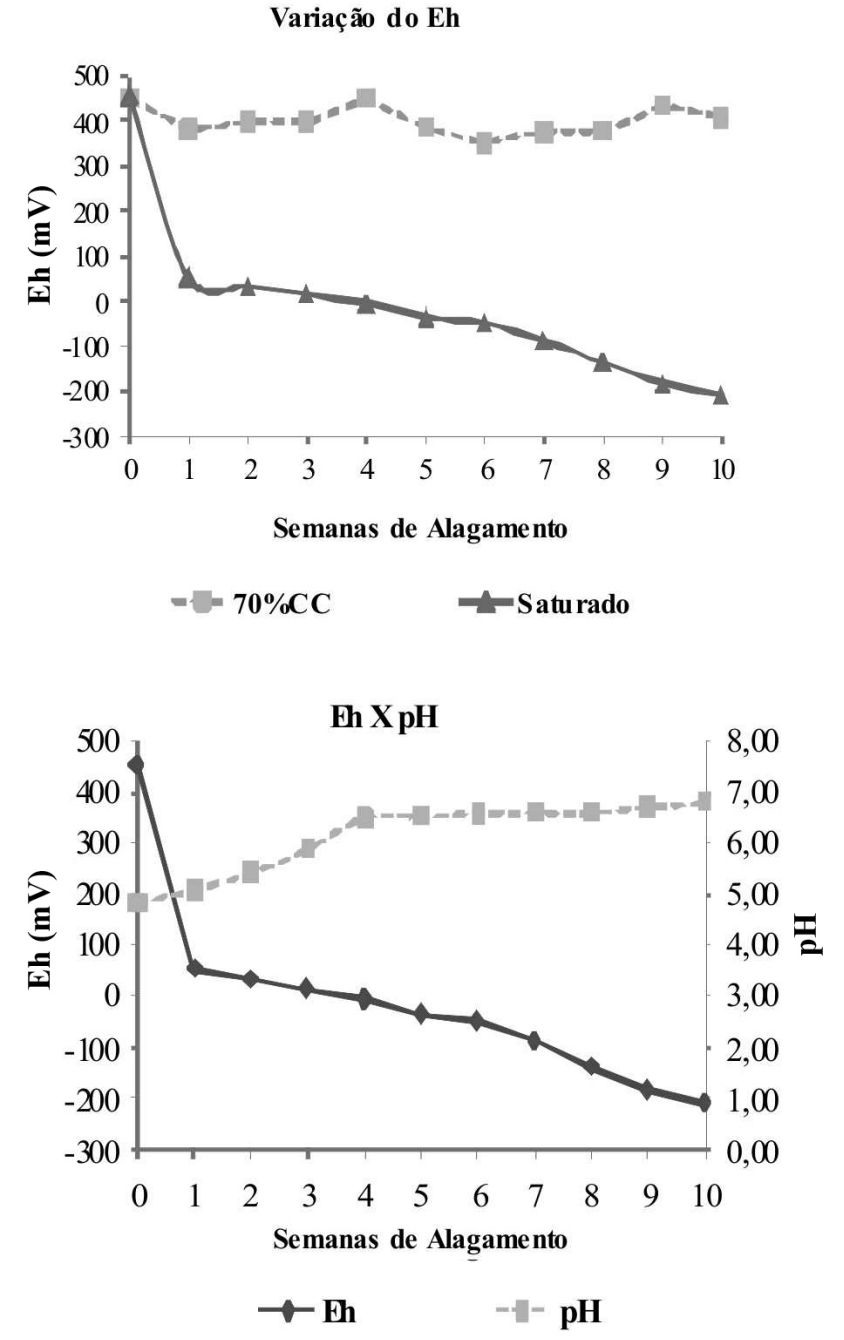

Figura 1. Variação do potencial redox (Eh) para os dois teores de umidade (A) e relação Eh - pH em função do tempo após o alagamento (B)

ambos os teores de umidade, a testemunha e a dose de $100 \mathrm{mg} \mathrm{kg}^{-1}$ não apresentaram diferença significativa, entretanto houve diferença dessas médias com as das doses de 300 e $3000 \mathrm{mg} \mathrm{kg}^{-1}$.

Observa-se que nas doses 1, 2 e 3 os maiores teores de bário se encontram na fração residual quando comparada com as demais frações. Esses resultados demonstram a baixa solubilidade da baritina,

Tabela 1. Distribuição do bário $\left(\mathrm{mg} \mathrm{kg}^{-1}\right)$ nas diferentes frações geoquímicas, em função da testemunha, doses e teor de umidade

\begin{tabular}{|c|c|c|c|c|c|c|}
\hline Fração & Umidade & Testemunha & Dose 1 & Dose 2 & Dose 3 & $\mathrm{CV}(\%)$ \\
\hline \multirow[t]{2}{*}{$\mathrm{F} 1$} & 70\% C.C & $17,6 \mathrm{Da}$ & $66,9 \mathrm{Ca}$ & $103 \mathrm{Ba}$ & $205,5 \mathrm{Ab}$ & 17,03 \\
\hline & Saturado & $28,5 \mathrm{Da}$ & $85,8 \mathrm{Ca}$ & $144,7 \mathrm{Ba}$ & $374,3 \mathrm{Aa}$ & \\
\hline \multirow[t]{2}{*}{ F2 } & 70\% C.C & $11,7 \mathrm{Da}$ & $25,7 \mathrm{Ca}$ & $59,7 \mathrm{Bb}$ & $142,6 \mathrm{Ab}$ & 12,74 \\
\hline & Saturado & 7,4 Da & $37,3 \mathrm{Ca}$ & $112,4 \mathrm{Ba}$ & $187,6 \mathrm{Aa}$ & \\
\hline \multirow[t]{2}{*}{ F3 } & 70\% C.C & $4,2 \mathrm{Da}$ & $11,5 \mathrm{Ca}$ & $28,9 \mathrm{Ba}$ & $175,3 \mathrm{Aa}$ & 17,4 \\
\hline & Saturado & $3,6 \mathrm{Da}$ & $15,2 \mathrm{Ca}$ & $39 \mathrm{Ba}$ & $140,1 \mathrm{Aa}$ & \\
\hline \multirow[t]{2}{*}{$\mathrm{F} 4$} & 70\% C.C & $189,5 \mathrm{Ca}$ & $218,9 \mathrm{Ca}$ & $297,4 \mathrm{Ba}$ & $2699,6 \mathrm{Aa}$ & 4,08 \\
\hline & Saturado & $183,5 \mathrm{Ca}$ & $184,8 \mathrm{Ca}$ & $224,1 \mathrm{Bb}$ & $2599,6 \mathrm{Ab}$ & \\
\hline
\end{tabular}

F1- Fração ácido solúvel; F2- Fração ligada a óxido de ferro e manganês; F3- Fração ligada à matéria orgânica e a sulfetos; F4- Residual. Letras seguidas de mesma letra (maiúsculas na linha e minúsculas na coluna) não diferem significativamente pelo teste de Tukey a 5\%. Testemunha- sem aplicação de bário; Dose 1- $100 \mathrm{mg} \mathrm{kg}^{-1}$; Dose 2- $300 \mathrm{mg} \mathrm{kg}^{-1}$ e Dose 3- $3000 \mathrm{mg} \mathrm{kg}^{-1}$. *As comparações das médias nas colunas referem-se às duas umidades para uma mesma fração de bário. 
visto que esta fração é a de maior estabilidade e recalcitrância. Smeda e Zyrnicki, ${ }^{19}$ estudando o fracionamento geoquímico do bário pelo método BCR, também identificaram maiores teores de bário na fração residual.

Avaliando o fracionamento geoquímico do bário em função dos teores de umidade observa-se que na fração ácido solúvel (F1) apenas na dose de $3000 \mathrm{mg} \mathrm{kg}^{-1}$ ocorreu aumento significativo $(\rho \leq 0,05)$ dos teores de bário na condição de redução. Esses resultados demonstram que solos altamente contaminados com baritina e em extrema redução $(-200 \mathrm{mV})$ poderá ocorrer a solubilização e liberação do bário no solo. Considerando-se que, essa fração é formada por íons livres em solução, metais ligados eletrostaticamente aos sítios de troca iônica existentes nas superfícies dos coloides do solo e os precipitados com carbonatos. ${ }^{20}$ Magalhães et al.,$^{8}$ estudando a mobilidade do bário em solos contaminados, sob as mesmas condições experimentais do presente estudo, também observaram aumento do elemento na fração F1 em solos reduzidos.

Em todas as doses, a condição de saturação não modificou a dinâmica do bário na fração ligada a matéria orgânica (F3), provavelmente, pela baixa afinidade do bário pelos sítios de ligação dos compostos orgânicos. ${ }^{21}$ Entretanto, na fração F4 as doses 300 e $3000 \mathrm{mg} \mathrm{kg}^{-1}$ apresentaram uma redução dos teores de bário na condição de saturação.

O teor médio de bário nos extratos lixiviados em função das diferentes doses, em meio oxidado e reduzido, é apresentado na Tabela 2. Observa-se que em condições de oxidação a testemunha e a dose de $100 \mathrm{mg} \mathrm{kg}^{-1}$ não diferiram estatisticamente ( $\rho \leq 0,05)$, entretanto as doses 300 e $3000 \mathrm{mg} \mathrm{kg}^{-1}$ apresentaram um aumento significativo do bário lixiviado. Em condições de redução houve aumento significativo do bário lixiviado com o aumento da concentração de bário no solo.

Tabela 2. Concentrações médias de bário $\left(\mathrm{mg} \mathrm{L}^{-1}\right)$ dos extratos lixiviados em função das doses e umidades

\begin{tabular}{lccccc}
\hline Umidade & Testemunha & Dose 1 & Dose 2 & Dose 3 & CV (\%) \\
\hline $70 \% \mathrm{CC}$ & $0,19 \mathrm{Ca}$ & $0,56 \mathrm{BCb}$ & $0,94 \mathrm{Bb}$ & $2,32 \mathrm{Ab}$ & 23,01 \\
Saturado & $0,07 \mathrm{Da}$ & $1,56 \mathrm{Ca}$ & $2,44 \mathrm{Ba}$ & $3,65 \mathrm{Aa}$ & \\
\hline
\end{tabular}

* Letras seguidas de mesma letra (maiúsculas na linha e minúsculas na coluna) não diferem significativamente pelo teste de Tukey a 5\%. Testemunha- sem aplicação de bário; Dose 1-100 mg kg ${ }^{-1}$; Dose 2- $300 \mathrm{mg} \mathrm{kg}^{-1}$ e Dose 3$3000 \mathrm{mg} \mathrm{kg}^{-1}$

A testemunha, em ambos os níveis de umidade, apresentou baixos teores de bário e não apresentou diferença significativa entre os solos oxidado e saturado. Quando comparados ao padrão de potabilidade de bário em águas $\left(0,7 \mathrm{mg} \mathrm{L}^{-1}\right),{ }^{13}$ observa-se que os teores estão abaixo deste padrão em condições de oxidação. Contudo, as doses de 100, 300 e $3000 \mathrm{mg} \mathrm{L}^{-1}$ apresentaram aumento significativo dos teores de bário no extrato lixiviado na condição de solo saturado. Na dose de $100 \mathrm{mg} \mathrm{kg}^{-1}$ a concentração de bário obtida no lixiviado foi de 1,6 mg L ${ }^{-1}$; na dose de $300 \mathrm{mg} \mathrm{kg}^{-1}$, o teor de bário foi de $2,4 \mathrm{mg} \mathrm{L}^{-1} \mathrm{e}$ para a maior dose (3000 $\left.\mathrm{mg} \mathrm{L}^{-1}\right)$ ficou próximo a $4 \mathrm{mg} \mathrm{L}^{-1}$. Observase que os teores de bário em todas as doses ficaram acima do valor máximo para potabilidade de água $\left(0,7 \mathrm{mg} \mathrm{L}^{-1}\right)$ evidenciando, assim, o risco de contaminação das águas subterrâneas. Resultados similares foram apresentados por Magalhães et al.,$^{8}$ em ensaio em colunas de lixiviação utilizando como fonte de bário o $\mathrm{BaSO}_{4}$ P.A.

A quantidade de bário acumulada em função das doses de baritina e condições de umidade são apresentadas na Figura 2. Verifica-se que na testemunha, em ambas as umidades, houve uma baixa remoção de bário nos volumes coletados. Este comportamento é evidenciado pela baixa inclinação da reta neste tratamento. Contudo, para os tratamentos que receberam diferentes doses de baritina houve uma diferença na remoção de bário entre os teores de umidade, mesmo para as menores doses. Comparando os resultados obtidos na dose $100 \mathrm{mg} \mathrm{kg}^{-1}$ com a testemunha observa-se que houve maior remoção, entretanto os teores removidos foram mais elevados no solo saturado, atingindo um total removido de $2,5 \mathrm{mg}$, enquanto que no solo oxidado foi apenas de $0,9 \mathrm{mg}$. Para a dose de $300 \mathrm{mg} \mathrm{kg}^{-1}$ também ocorreu maior remoção de bário em condição de saturação, sendo $1,5 \mathrm{mg}$ para solo oxidado e 3,9 mg para solo saturado. Na maior dose para o solo com teor de umidade a $70 \%$ da capacidade de campo, verifica-se que o total de bário removido foi de $3,7 \mathrm{mg}$, enquanto que no solo saturado a remoção foi superior, apresentando valores de $6,8 \mathrm{mg}$, cerca de $50 \%$ mais elevado. Diante dos resultados apresentados observa-se que a condição de redução promoveu maior solubilidade do bário e, consequentemente, maior lixiviação.
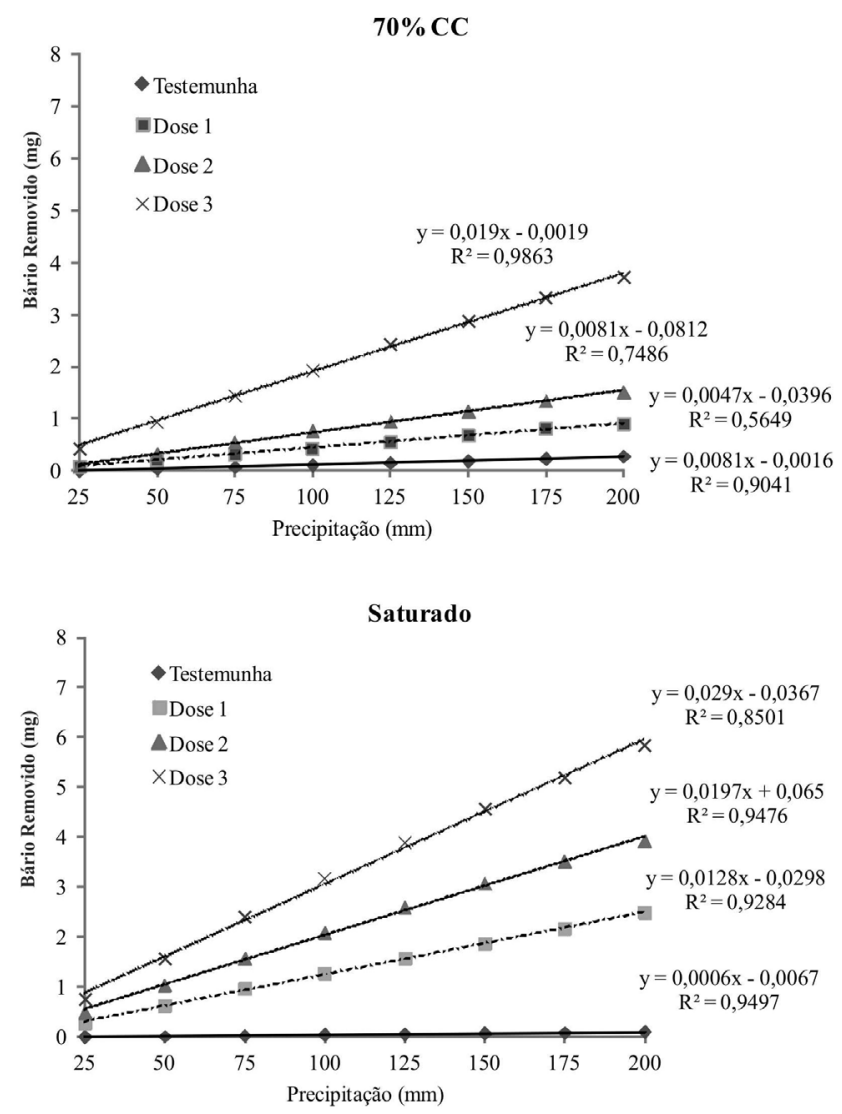

Figura 2. Quantidade de bário $(\mathrm{mg})$ removido em cada volume em função da doses e condições de umidade

O desenvolvimento das plantas de arroz foi avaliado pela produção de matéria seca da parte área, raiz, grãos cheios, grãos vazios e o total da planta, em função das diferentes doses e umidades (Tabela 3).

A produção de matéria seca da parte aérea foi influenciada pelas diferentes doses e umidades, apresentando diferença significativa. A biomassa dos grãos cheios também apresentou diferença significativa entre a testemunha e as diferentes doses quando as plantas foram cultivadas em solo oxidado, sendo o maior valor encontrado na testemunha $(6,8 \mathrm{~g})$ e o menor na dose de $3000 \mathrm{mg} \mathrm{kg}^{-1}$ de bário $(1,4 \mathrm{~g})$. No solo saturado observa-se diferença significativa somente entre a testemunha e as maiores doses ( $300 \mathrm{e} 3000 \mathrm{mg} \mathrm{kg}^{-1}$ ). A massa seca dos grãos cheios também foi influenciada pelas condições de umidade, onde os maiores valores se encontram para o solo oxidado.

A produção total de massa seca das plantas de arroz apresentou diferença significativa entre a testemunha e as doses de 300 e 
Tabela 3. Produção de matéria seca (g) das plantas de arroz, em função das doses de bário e condições de umidade

\begin{tabular}{|c|c|c|c|c|c|c|}
\hline & Umidade & Testemunha & Dose 1 & Dose 2 & Dose 3 & $\mathrm{CV}(\%)$ \\
\hline \multirow[t]{2}{*}{ Parte aérea } & $70 \% \mathrm{CC}$ & $15,7 \mathrm{Aa}$ & $15,6 \mathrm{Aa}$ & $17,5 \mathrm{Aa}$ & $17,2 \mathrm{Aa}$ & 3,10 \\
\hline & Saturado & $17,4 \mathrm{Aa}$ & $16,8 \mathrm{Aa}$ & $15,6 \mathrm{Aa}$ & $15,1 \mathrm{Ab}$ & \\
\hline \multirow[t]{2}{*}{ Raiz } & $70 \% \mathrm{CC}$ & $14,6 \mathrm{Aa}$ & $15,9 \mathrm{Aa}$ & $15,5 \mathrm{Aa}$ & $16,4 \mathrm{Aa}$ & 6,30 \\
\hline & Saturado & $14,6 \mathrm{Aa}$ & $15,9 \mathrm{Aa}$ & $14,7 \mathrm{Aa}$ & $15,3 \mathrm{Aa}$ & \\
\hline \multirow[t]{2}{*}{ Grãos cheios } & $70 \% \mathrm{CC}$ & $6,8 \mathrm{Aa}$ & $4,5 \mathrm{Ba}$ & $3,8 \mathrm{Ba}$ & $1,4 \mathrm{Ca}$ & 15,85 \\
\hline & Saturado & $0,9 \mathrm{Ab}$ & $0,4 \mathrm{ABb}$ & $0,2 \mathrm{Bb}$ & $0,3 \mathrm{Bb}$ & \\
\hline \multirow[t]{2}{*}{ Grãos vazios } & $70 \% \mathrm{CC}$ & $0,2 \mathrm{Ba}$ & $0,6 \mathrm{Aa}$ & $0,7 \mathrm{Aa}$ & $0,6 \mathrm{Ab}$ & 20,47 \\
\hline & Saturado & $1,0 \mathrm{Ab}$ & $0,8 \mathrm{Aa}$ & $0,8 \mathrm{Aa}$ & $0,8 \mathrm{Aa}$ & \\
\hline \multirow[t]{2}{*}{ Total grãos } & $70 \% \mathrm{CC}$ & 7,0 Aa & $5,2 \mathrm{Ba}$ & $4,5 \mathrm{Ba}$ & $2,0 \mathrm{Ca}$ & 18,55 \\
\hline & Saturado & $1,9 \mathrm{Ab}$ & $1,3 \mathrm{Ab}$ & $1,0 \mathrm{Ab}$ & $1,1 \mathrm{Ab}$ & \\
\hline \multirow[t]{2}{*}{ Total planta } & $70 \% \mathrm{CC}$ & $37,4 \mathrm{Aa}$ & $36,6 \mathrm{Aa}$ & $37,5 \mathrm{Aa}$ & $35,6 \mathrm{Aa}$ & 3,20 \\
\hline & Saturado & $33,9 \mathrm{Ab}$ & $34,0 \mathrm{Ab}$ & $31,3 \mathrm{Bb}$ & $31,5 \mathrm{Bb}$ & \\
\hline
\end{tabular}

*Letras seguidas de mesma letra (maiúsculas na linha e minúsculas na coluna) não diferem significativamente pelo teste de Tukey a 5\%. Testemunha - sem aplicação de baritina; Dose 1 - $100 \mathrm{mg} \mathrm{kg}^{-1}$; Dose 2 - $300 \mathrm{mg} \mathrm{kg}^{-1}$ e Dose $3-3000 \mathrm{mg} \mathrm{kg}^{-1}$.

$3000 \mathrm{mg} \mathrm{kg}^{-1}$ quando cultivado em condições de saturação. Quando se analisa a diferença entre umidades, observa-se que houve uma redução significativa de massa nas plantas cultivadas em solo saturado.

De acordo com os resultados, observa-se que o desenvolvimento das plantas de arroz foi afetado de forma negativa pela condição de saturação, sendo que as plantas cultivadas sob esta condição apresentaram menor biomassa total e menor produção de grãos cheios. Esses resultados diferem dos encontrados por Patel et al., ${ }^{22}$ que verificaram uma redução média de $27 \%$ no rendimento de plantas cultivadas sob solos em condições aeróbicas, quando comparadas com cultivo inundado. A baixa produção das plantas de arroz sob condições de redução pode não estar associada somente ao bário, visto que a testemunha também apresentou redução na biomassa dos grãos. A dissolução redutiva dos óxidos de ferro e manganês pode ter liberado quantidades significativas no solo, promovendo uma maior absorção, ocasionando fitotoxidade (Tabela $2 \mathrm{~S}$, material suplementar).

A concentração de bário na parte aérea foi influenciada pelas doses apenas no solo saturado, onde a dose de $3000 \mathrm{mg} \mathrm{kg}^{-1}$ apresentou aumento significativo em relação às doses de 100 e $300 \mathrm{mg} \mathrm{kg}^{-1}$ e a testemunha (Tabela 4). Apesar de não ocorrer diferença entre as doses de 100 e $300 \mathrm{mg} \mathrm{kg}^{-1}$, estas diferiram significativamente quando comparadas à condição natural do solo. Observa-se que o teor de umidade do solo também influenciou nas concentrações de bário, sendo os maiores valores encontrados no solo sob saturação.

Para a condição de maior restrição (solo saturado e maior dose) verifica-se que a concentração de bário foi de $573 \mathrm{mg} \mathrm{kg}^{-1}$. Apesar

Tabela 4. Concentração $\left(\mathrm{mg} \mathrm{kg}^{-1}\right)$ e acúmulo de bário $\left(\mathrm{mg} \mathrm{vaso}^{-1}\right)$ na parte aérea, raiz e grãos das plantas de arroz, nas diferentes doses de bário e condições de umidade

\begin{tabular}{|c|c|c|c|c|c|c|}
\hline & Umidade & Testemunha & Dose 1 & Dose 2 & Dose 3 & $\mathrm{CV}(\%)$ \\
\hline \multirow[t]{2}{*}{ Parte aérea } & 70\% C.C & $141 \mathrm{Aa}$ & $151 \mathrm{Ab}$ & $132 \mathrm{Ab}$ & $141 \mathrm{Ab}$ & 13,65 \\
\hline & Saturado & $126 \mathrm{Ca}$ & $276 \mathrm{Ba}$ & $304 \mathrm{Ba}$ & $573 \mathrm{Aa}$ & \\
\hline \multirow[t]{2}{*}{ Raiz } & 70\% C.C & $57 \mathrm{Ca}$ & $292 \mathrm{Ba}$ & $564 \mathrm{Aa}$ & $689 \mathrm{Ab}$ & 20,98 \\
\hline & Saturado & $50 \mathrm{Ca}$ & $195 \mathrm{Ca}$ & $529 \mathrm{Ba}$ & $896 \mathrm{Aa}$ & \\
\hline \multirow[t]{4}{*}{ Grãos } & 70\% C.C & $47 \mathrm{Aa}$ & $38 \mathrm{Aa}$ & $34 \mathrm{Aa}$ & $40 \mathrm{Aa}$ & 16,65 \\
\hline & Saturado & $54 \mathrm{Aa}$ & $52 \mathrm{Aa}$ & $51 \mathrm{Aa}$ & $46 \mathrm{Aa}$ & \\
\hline & \multicolumn{6}{|c|}{------1 } \\
\hline & Umidade & Testemunha & Dose 1 & Dose 2 & Dose 3 & $\mathrm{CV}(\%)$ \\
\hline \multirow[t]{2}{*}{ Parte aérea } & $70 \%$ C.C & $2,2 \mathrm{Aa}$ & $2,4 \mathrm{Ab}$ & $2,3 \mathrm{Ab}$ & $2,4 \mathrm{Ab}$ & 15,48 \\
\hline & Saturado & $2,2 \mathrm{Ca}$ & $4,7 \mathrm{Ba}$ & $4,8 \mathrm{Ba}$ & $8,7 \mathrm{Aa}$ & \\
\hline \multirow[t]{2}{*}{ Raiz } & $70 \%$ C.C & $0,8 \mathrm{Da}$ & $4,6 \mathrm{Ca}$ & $8,8 \mathrm{Ba}$ & $11,2 \mathrm{Ab}$ & 18,79 \\
\hline & Saturado & $0,7 \mathrm{Da}$ & $3,1 \mathrm{Ca}$ & 7,7 Ba & $13,7 \mathrm{Aa}$ & \\
\hline \multirow[t]{2}{*}{ Grãos } & 70\% C.C & $0,3 \mathrm{Aa}$ & $0,2 \mathrm{Ba}$ & $0,2 \mathrm{Ba}$ & $0,1 \mathrm{Ca}$ & 27,54 \\
\hline & Saturado & $0,1 \mathrm{Ab}$ & $0,1 \mathrm{Ab}$ & $0,1 \mathrm{Ab}$ & $0,1 \mathrm{Aa}$ & \\
\hline \multirow[t]{2}{*}{ Total } & 70\% C.C & $3,4 \mathrm{Da}$ & $7,1 \mathrm{Ca}$ & $11,2 \mathrm{Ba}$ & $13,7 \mathrm{Ab}$ & 11,23 \\
\hline & Saturado & $3,0 \mathrm{Da}$ & $7,8 \mathrm{Ca}$ & $12,6 \mathrm{Ba}$ & $22,4 \mathrm{Aa}$ & \\
\hline
\end{tabular}

*Letras seguidas de mesma letra (maiúsculas na linha e minúsculas na coluna) não diferem significativamente pelo teste de Tukey a 5\%. Testemunha- sem aplicação de baritina; Dose 1- $100 \mathrm{mg} \mathrm{kg}^{-1}$; Dose 2- $300 \mathrm{mg} \mathrm{kg}^{-1}$; Dose 3- $3000 \mathrm{mg} \mathrm{kg}^{-1}$ 
de poucas informações na literatura sobre a toxicidade de bário em plantas, estudos realizados por Pais e Jones Jr., ${ }^{23}$ relatam concentrações acima de $500 \mathrm{mg} \mathrm{kg}^{-1}$ como tóxica para as plantas.

Nas raízes das plantas que se desenvolveram em solo oxidado, a menor concentração de bário foi na testemunha $\left(57 \mathrm{mg} \mathrm{kg}^{-1}\right)$. Quando aplicadas às doses de baritina, verifica-se aumento significativo, entretanto não houve diferença entre as maiores doses. Para a condição de saturação as raízes não apresentaram diferença nos teores de bário entre a testemunha e a dose de $100 \mathrm{mg} \mathrm{kg}^{-1}$, no entanto houve diferença dessas médias com as médias das doses de $300 \mathrm{mg} \mathrm{kg}^{-1}$ (529 $\mathrm{mg} \mathrm{kg}^{-1}$ ) e de $3000 \mathrm{mg} \mathrm{kg}^{-1}$ (896 mg kg${ }^{-1}$ ). As condições de umidade influenciaram nos teores de bário apenas para a maior dose, onde o maior valor foi na condição de saturação.

Não há evidências de que o bário seja um elemento essencial em plantas ${ }^{1}$ e, também, são limitadas as informações disponíveis sobre o efeito do bário nas atividades fisiológicas. ${ }^{5}$ Entretanto, em estudo realizado com soja cultivada em solução nutritiva, Suwa et al. ${ }^{10}$ avaliaram a atividade fotossintética foliar como um indicador do efeito de bário em plantas e verificaram que todos os tratamentos com bário reduziram significativamente a atividade fotossintética, afetando o desenvolvimento das plantas, principalmente a produtividade.

Quanto ao total de bário absorvido pelas plantas de arroz observa-se que em ambas as umidades houve aumento significativo de bário com o aumento da concentração de bário no solo, sendo que o maior valor foi encontrado na maior dose $(13,74 \mathrm{mg}$ para a condição de oxidação e $22,39 \mathrm{mg}$ para a condição de saturação). A condição de extrema redução promoveu aumento significativo apenas na maior dose. Llugany et al. ${ }^{24}$ também observaram que com o aumento da concentração de bário no solo, as plantas acumularam maior quantidade de bário.

Com o objetivo de ratificar os resultados obtidos, foi realizada a análise de correlação de Pearson entre o bário extraído na fração F1 e a concentração nas diferentes partes vegetais, em função das umidades (Tabela 3S, material suplementar). Verifica-se que na condição de oxidação não houve correlação da concentração de bário na fração ácido solúvel com a concentração de bário na parte aérea e nos grãos, apresentando correlação alta e significativa apenas com a concentração das raízes $\left(r=0,98^{* *}\right)$. Para a condição de redução, entretanto, observa-se alta e significativa correlação da F1 com a concentração da parte aérea $\left(\mathrm{r}=0,98^{* *}\right)$ e das raízes $\left(\mathrm{r}=0,99^{* *}\right)$.

Diante do exposto, verifica-se que a condição de redução promoveu as maiores correlações quando comparadas com a condição de oxidação. Isso evidencia que os maiores teores de bário encontrados na fração F1 para a condição de redução estão associados à solubilização e liberação do bário no solo promovendo, assim, maior absorção do elemento pelas plantas de arroz.

\section{CONCLUSÃO}

Em altas concentrações de bário no solo, a condição de redução propiciou o aumento dos teores do elemento na fração ácido solúvel.

Em condição de saturação, a adição de baritina ao solo promoveu maiores teores de bário no extrato lixiviado, onde os valores se encontram acima dos padrões para potabilidade de água $\left(0,7 \mathrm{mg} \mathrm{L}^{-1}\right)$ evidenciando, assim, o risco de contaminação das águas subterrâneas.

As plantas, quando cultivadas em ambiente com altos teores de baritina e sob condição de saturação, apresentaram maior absorção de bário e redução da biomassa da parte aérea.

\section{MATERIAL SUPLEMENTAR}

O material suplementar, disponível em http://quimicanova.sbq. org.br, em arquivo pdf e com acesso livre, apresenta tabela com os teores pseudototais de metais na baritina (Tabela $1 \mathrm{~S}$ ); as concentrações de Fe e Mn nas plantas de arroz (Tabela 2S) e os coeficientes de correlação de Pearson entre o bário extraído na F1 e a concentração nas diferentes partes vegetais, em função das umidades (Tabela 3S).

\section{REFERÊNCIAS}

1. World Health Organization; Environmental health criteria 107, Geneva. 1990.

2. http://www.dnpm.gov.br/assets/galeriadocumento/balancomineral2001/ barita.pdf, acessada em Agosto 2012; Fam, M. A.; Dusseault, M. B.; Fooks, J. C.; J. Pet. Sci. Eng. 2003, 38, 155; Pozebon, D.; Lima, E. C.; Maia, S. M.; Fachel, J. M. G.; Fuel 2005, 84, 53.

3. Sousa, R. O.; Vahl, L. C.; Otero, X. L. Em Química e Mineralogia do Solo. Parte II - Aplicações; Mello, V. F.; Alleoni, L. R. F., eds.; Sociedade Brasileira de Ciência do Solo: Viçosa, 2009, cap. 2.

4. Raghu, V.; Environ. Geology. 2001, 40, 1265.

5. http://www.epa.gov/iris/toxreviews/0010tr.pdf, acessada em Agosto 2012.

6. Seybold, C. A.; Mersie, W.; Huang, J.; McNamee, C.; Wetlands 2002, $22,149$.

7. Phillips, E. J. P.; Landa, E. R.; Kraemer, T.; Zielinski, R.; Geomicrobiology 2001, 18, 167; Ulrich, G. A.; Breit, G. N.; Cozzarelli, I. M.; Suflita, J. M.; Environ. Sci. Technol. 2003, 37, 1093.

8. Magalhães, M. O. L.; Amaral Sobrinho, N. M. B.; Zonta, E.; Lima, L. S.; Paiva, F. S. D.; Quim. Nova 2011, 34, 1544.

9. Magalhães, M. O. L.; Tese de Doutorado, Universidade Federal Rural do Rio de Janeiro, Brasil, 2011.

10. Suwa, R.; Jayachandran, K.; Nguyen, N. T.; Boulenouar, A.; Fujita, K.; Saneoka, H.; Arch. Environ. Contam. Toxicol. 2008, 55, 397.

11. Empresa Brasileira de Pesquisa Agropecuária; Manual de métodos de análises de solos, $2^{\text {a }}$ ed., CNPS: Rio de Janeiro, 1997.

12. International Organization for Standardization; Soil quality-Extraction of trace elements soluble in aqua regia, Geneva, 1995.

13. Brasil, Conselho Nacional do Meio Ambiente; Resolução CONAMA $n^{o}$. 420 , de 28/12/2009.

14. Ure, A.; Quevauviller, P. H.; Muntau, H.; Griepink, B.; Int. J. Environ. Anal. Chem. 1993, 51, 135.

15. Tedesco, M. J.; Gianelo, C.; Bissani, C. A.; Bohnen, H.; Wolkweiss, S. J.; Análises de solos, plantas e outros materiais, $2^{\mathrm{a}}$ ed., UFRGS: Porto Alegre, 1995.

16. Camargo, O. A.; Alleoni, L. R. F.; Casagrande, J. C. Em Micronutrientes e elementos tóxicos na agricultura; Ferreira, M. E.; Cruz, M. C. P.; van Raij, B.; Abreu, C. A., eds.; POTAFOS: Jaboticabal, 2001, cap. 5.

17. Lima, E. N.; Mello, J. W. V.; Schaefer, C. E. G. R.; Ker, J. C.; Acta Amazônica 2005, 35, 317.

18. Sparks, D. L.; Environmental Soil Chemistry, Academic Press: San Diego, 1995.

19. Smeda, A.; Zyrnicki, W.; Microchem. J. 2002, 72, 9.

20. Filgueiras, A. V.; Lavilla, I.; Bendicho, C.; Sci. Total Environ. 2004, 330, 115.

21. World Health Organization; Concise International Chemical Assessment Document 33, Geneva, 2001.

22. Patel, D. P.; Das, A.; Munda, G. C.; Ghosh, P. K.; Bordoloi, J. S.; Kumar, M.; Agricultural Water Management 2010, 97, 1269.

23. Pais, I.; Jones Jr, J. B.; The Handbook of Trace Elements, St. Lucie Press: Boca Raton, 1998.

24. Llugany, M.; Poschenrieder, C.; Barcelo, L.; Arch. Environ. Contam. Toxicol. 2000, 39, 440. 


\section{ABSORÇÃO DE BÁRIO POR PLANTAS DE ARROZ (Oryza sativa L.) E MOBILIDADE EM SOLO TRATADO COM BARITINA SOB DIFERENTES CONDIÇÕES DE POTENCIAL REDOX}

Erica Souto Abreu Lima*, Nelson Moura Brasil do Amaral Sobrinho, Marcio Osvaldo Lima Magalhães, Jair do Nascimento Guedes e Everaldo Zonta

Departamento de Solos, Instituto de Agronomia, Universidade Federal Rural do Rio de Janeiro, BR 465, km 7, 23890-000 Seropédica - RJ, Brasil

Tabela 1S. Teores pseudototais de metais pesados na fonte de baritina

\begin{tabular}{ccc}
\hline Parâmetros & Unidades & Baritina \\
\hline Bário & $\%$ & 58,04 \\
Arsênio & $\mathrm{mg} \mathrm{kg}^{-1}$ & 5,016 \\
Cádmio & $\mathrm{mg} \mathrm{kg}^{-1}$ & 0,065 \\
Mercúrio & $\mathrm{mg} \mathrm{kg}^{-1}$ & 0,346 \\
Ferro & $\mathrm{mg} \mathrm{kg}^{-1}$ & 16571,93 \\
Manganês & $\mathrm{mg} \mathrm{kg}^{-1}$ & 59,54 \\
Zinco & $\mathrm{mg} \mathrm{kg}^{-1}$ & 13 \\
\hline
\end{tabular}

Tabela 2S. Concentração de Fe e $\mathrm{Mn}\left(\mathrm{mg} \mathrm{kg}^{-1}\right)$ nas diferentes partes vegetais das plantas de arroz, em função das doses de bário e condições de umidade

\begin{tabular}{|c|c|c|c|c|c|c|}
\hline \multicolumn{7}{|c|}{ Ferro } \\
\hline & & Testemunha & Dose 1 & Dose 2 & Dose 3 & $\mathrm{CV}(\%)$ \\
\hline \multirow[t]{2}{*}{ Parte aérea } & $70 \%$ C.C & $99 \mathrm{Ab}$ & $96 \mathrm{Ab}$ & $118 \mathrm{Ab}$ & $118 \mathrm{Ab}$ & 4,15 \\
\hline & Saturado & $413 \mathrm{Aa}$ & $586 \mathrm{Aa}$ & $557 \mathrm{Aa}$ & $525 \mathrm{Aa}$ & \\
\hline \multirow[t]{2}{*}{ Raiz } & 70\% C.C & $13059 \mathrm{Bb}$ & $11619 \mathrm{Bb}$ & $10558 \mathrm{Bb}$ & $39077 \mathrm{Ab}$ & 13,14 \\
\hline & Saturado & 87523 Aa & $87318 \mathrm{Aa}$ & 89812 Аa & $70613 \mathrm{Ba}$ & \\
\hline \multirow[t]{4}{*}{ Grãos } & $70 \%$ C.C & $64 \mathrm{Ab}$ & $48 \mathrm{Ab}$ & $61 \mathrm{Ab}$ & $48 \mathrm{Ab}$ & 30,04 \\
\hline & Saturado & $124 \mathrm{Ba}$ & $225 \mathrm{Aa}$ & $223 \mathrm{Aa}$ & $232 \mathrm{Aa}$ & \\
\hline & & \multicolumn{3}{|c|}{ Manganês } & & \\
\hline & & Testemunha & Dose 1 & Dose 2 & Dose 3 & $\mathrm{CV}(\%)$ \\
\hline \multirow[t]{2}{*}{ Parte aérea } & $70 \%$ C.C & $2978 \mathrm{Ab}$ & $3109 \mathrm{Ab}$ & $3093 \mathrm{Ab}$ & $3211 \mathrm{Aa}$ & 9,84 \\
\hline & Saturado & 3942 Aa & $3971 \mathrm{Aa}$ & $3610 \mathrm{Aa}$ & $3539 \mathrm{Aa}$ & \\
\hline \multirow[t]{2}{*}{ Raiz } & $70 \%$ C.C & $305 \mathrm{Bb}$ & $259 \mathrm{Bb}$ & $215 \mathrm{Bb}$ & $829 \mathrm{Ab}$ & 26,59 \\
\hline & Saturado & $829 \mathrm{Ba}$ & $847 \mathrm{ABa}$ & $831 \mathrm{ABa}$ & $1173 \mathrm{Aa}$ & \\
\hline \multirow[t]{2}{*}{ Grãos } & $70 \%$ C.C & $1089 \mathrm{Aa}$ & $1069 \mathrm{Aa}$ & $1036 \mathrm{Aa}$ & $1171 \mathrm{Aa}$ & 24,99 \\
\hline & Saturado & $1009 \mathrm{Aa}$ & $1051 \mathrm{Aa}$ & $1174 \mathrm{Aa}$ & $1280 \mathrm{Aa}$ & \\
\hline
\end{tabular}

*Letras seguidas de mesma letra (maiúsculas na linha e minúsculas na coluna) não diferem significativamente pelo teste de Tukey a 5\%. Testemunha- sem aplicação de baritina; Dose 1- $100 \mathrm{mg} \mathrm{kg}^{-1}$, Dose 2 - $300 \mathrm{mg} \mathrm{kg}^{-1}$, Dose 3 - $3000 \mathrm{mg} \mathrm{kg}^{-1}$

Tabela 3S. Coeficientes de correlação de Pearson entre o bário extraído na fração ácido solúvel (F1) e as concentrações nas diferentes partes vegetais, em função das umidades

\begin{tabular}{cccc}
\hline \multicolumn{2}{c}{ Correlação } & Oxidado & Reduzido \\
\hline Concentração & Folha & $-0,34$ & $0,98 * *$ \\
& Raiz & $0,98 * *$ & $0,99 * *$ \\
& Grãos & $-0,49$ & $-0,82$ \\
\hline
\end{tabular}

** significativo ao nível de $1 \%$; * significativo ao nível de $5 \%$. 